\title{
A FORMAÇÃO PROFISSIONAL EM EDUCAÇÃO FÍSICA E O PROCESSO POLÍTICO SOCIAL
}

\author{
Ana Márcia Silva
}

Universidade Federal de Goiás, Goiânia, Goiás, Brasil.

\author{
Aline da Silva Nicolino \\ Universidade Federal de Goiás, Goiânia, Goiás, Brasil.
}

Humberto Luís de Deus Inácio

Universidade Federal de Goiás, Goiânia, Goiás, Brasil.

\section{Valéria Maria Chaves de Figueiredo}

Universidade Federal de Goiás, Goiânia, Goiás, Brasil.

\begin{abstract}
Resumo
Este artigo discute alguns determinantes que permeiam a formação profissional em Educação Física no Brasil. A pesquisa, de tipo documental com técnica de análise de conteúdo, trabalhou com documentos e bancos de dados oficiais do governo brasileiro, além de outros provenientes de organismos internacionais. Os dados da investigação apontam que mais de 100 mil vagas são abertas a cada ano em cursos superiores de Educação Física, tornando-o um dos 10 maiores em número de concluintes no país. Observamse, ainda, elementos político-econômicos vinculados aos interesses e demandas emergentes de mercado, os quais direcionam as necessidades do processo social na formação profissional em Educação Física.

Palavras-chave: Educação Física - Formação Profissional - Políticas Educacionais.
\end{abstract}

$\mathrm{E}$ ste artigo resulta de investigações de alguns determinantes político-econômicos que permeiam a formação profissional em Educação Física no Brasil. Para tal, recorremos a documentos oficiais de políticas públicas e bancos de dados do governo brasileiro, notadamente, do Instituto Nacional de Estudos e Pesquisas Educacionais Anísio Teixeira (INEP) vinculado ao Ministério da Educação (MEC) e do Sistema Nacional de Avaliação da Educação Superior (SINAES), instituído pelo Presidente da República em forma de Lei n ${ }^{\circ}$ 10.861, em 2004 (BRASIL, 2004) com a finalidade de avaliar o ensino superior, também vinculado ao INEP. Utilizamos, ainda, outras fontes documentais provenientes de organismos internacionais, tais como o Banco Mundial, a Organização Mundial do Comércio e a Organização das Nações Unidas para a Educação, a Ciência e a Cultura (UNESCO), buscando analisar alguns interesses que atuam neste campo acadêmico-profissional, como em outros relacionados a Educação.

A hipótese de trabalho que levantamos para a compreensão destes dados situa-se na perspectiva de que a ampliação da oferta no ensino superior em Educação Física é decorrente do fato de que este é um campo acadêmico-profissional em expansão, especialmente, como comercialização da formação superior. As práticas corporais, direta ou indiretamente, também se constituem em um nicho de mercado em expansão, com todas as contradições aí implicadas. Tal perspectiva parece estar presente desde sua constituição como formação emergencial até a segunda década do século XX Ao atender a este mercado de formação e de intervenção profissional com as práticas corporais, nossa hipótese é de que as dicotomias e dualidades, tais como teoria e prática, licenciatura e 
bacharelado, trabalho mental e manual, foram se acirrando, com uma fragmentação do campo e consequente no reducionismo na concepção de ser humano.

A análise desses dados e documentos nos permitiu, entre outras coisas, melhor compreender como algumas políticas públicas vêm sendo construídas, reproduzidas e aplicadas ao longo do processo educativo, sobretudo no cotidiano das instituições de ensino superior e das atuações profissionais. Alguns indicadores apontam para a força dos determinantes econômicos, sobretudo em países como o Brasil que se movem pela lógica do capital, os quais merecem maior atenção, dado que se desdobram na vida coletiva em sociedade e, especialmente, em um campo de atuação como a educação, grande responsável pela formação de novas gerações.

Pesquisas desta natureza visam, ainda, construir referências para melhor compreender as identidades assumidas pelos professores, sobretudo no cotidiano escolar, assim como na atuação como profissional liberal, compondo preferências, valores e comportamentos, bem como cristalizando o senso comum, dualidades e contradições da formação profissional no campo da Educação Física, como demonstram investigações anteriores (DAVID, 2002, 2009; PAIVA; ANDRADE FILHO; FIGUEIREDO, 2006; TAFFAREL; LACKS; SANTOS JÚNIOR, 2006), entre outras.

\section{Indicadores do ensino superior no brasil: um enfoque na formação em educação física}

Dentre os indicadores que geraram esta pesquisa, encontra-se o forte crescimento na oferta de vagas em Cursos Superiores de Educação Física no país, indicador este que chama a atenção, sobretudo, porque mostra-se acima da média de crescimento geral dos cursos neste nível de ensino. No Brasil, para o ano de 1991, encontramos o registro de 117 cursos. Atualmente, segundo números apresentados no portal do SINAES, encontra-se o cadastrado de 1031 cursos de graduação em Educação Física. Esta curva de crescimento mostra que, no espaço de dezesseis anos, a oferta de Cursos Superiores neste campo cresceu 881\%. Tais informações podem ser melhor exploradas no gráfico que segue.

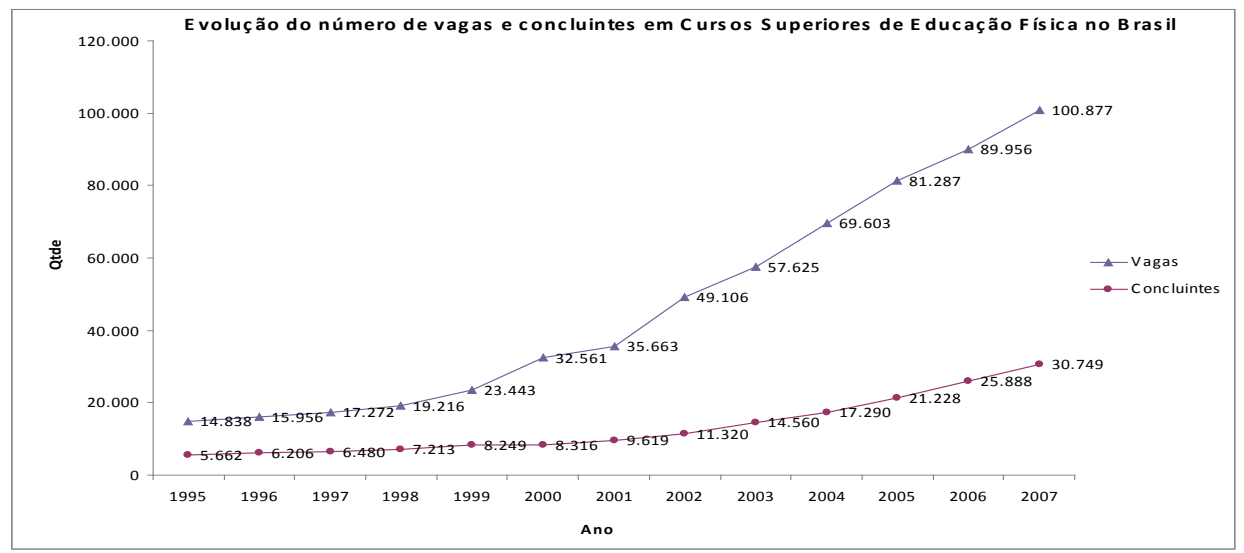

Figura 1. Gráfico de distribuição percentual evolutiva do número de vagas e concluintes em cursos superiores de Educação Física. 
Os cursos de Educação Física integram o contexto de significativo crescimento do ensino superior no Brasil, apresentando um aumento no número de vagas e concluintes de, aproximadamente, 680\% e 543\% respectivamente, entre 1995 a 2007. Vale ressaltar que neste mesmo período o percentual de concluintes de todos os cursos aumentou 297,48\%, número muito inferior ao crescimento dos concluintes em Educação Física, como mostra a comparação.

Observa-se que, no período de 1995 a 1998, o crescimento médio anual da oferta do número de vagas nos cursos de Educação Física era de aproximadamente 7,83\%. No período entre 1999 e 2007, o crescimento médio anual foi de 20,65\%, apontando assim uma aceleração acentuada a partir de 1998, período em que se registra a regulamentação da profissão, sob Lei $n^{\circ}$ 9.696/98 a qual entra em vigor no dia primeiro de setembro de 1998.

Compondo este contexto, de acordo com o INEP (1998), identificamos que no ano de 1997 eram titulados em Educação Física 6.480 novos professores, sendo o $13^{\circ}$ em quantidade de concluintes[1]. Segundo a mesma fonte, no ano de 2007 este número elevou-se para 30.749 e a Educação Física passou a ocupar o $8^{\circ}$ lugar em número de concluintes[2], dado que reafirma um crescimento da oferta de vagas, assim como de concluintes, muito acima da média nacional no ensino superior.

Dentre estes dados e para o mesmo ano indicado anteriormente, identifica-se que o enorme crescimento é responsabilidade da iniciativa privada, sendo que, para a formação em nível superior, aproximadamente $89 \%$ é feita pelas instituições privadas. Santos e Simões (2008) também indicam este crescimento expressivo, sobretudo, do setor privado, com referência ao número de cursos e consequentemente de vagas ofertadas para a Educação Física, os quais mostram que em 2004 as instituições públicas respondiam por 33,68\% enquanto as instituições privadas representavam $66,32 \%$. No ano de 2007 , esse percentual aumenta para o ensino privado, segundo portal do INEP, o salto de crescimento foi de $79,8 \%$ das vagas oferecidas para os cursos de Educação Física[3], como pode-se acompanhar no gráfico abaixo.

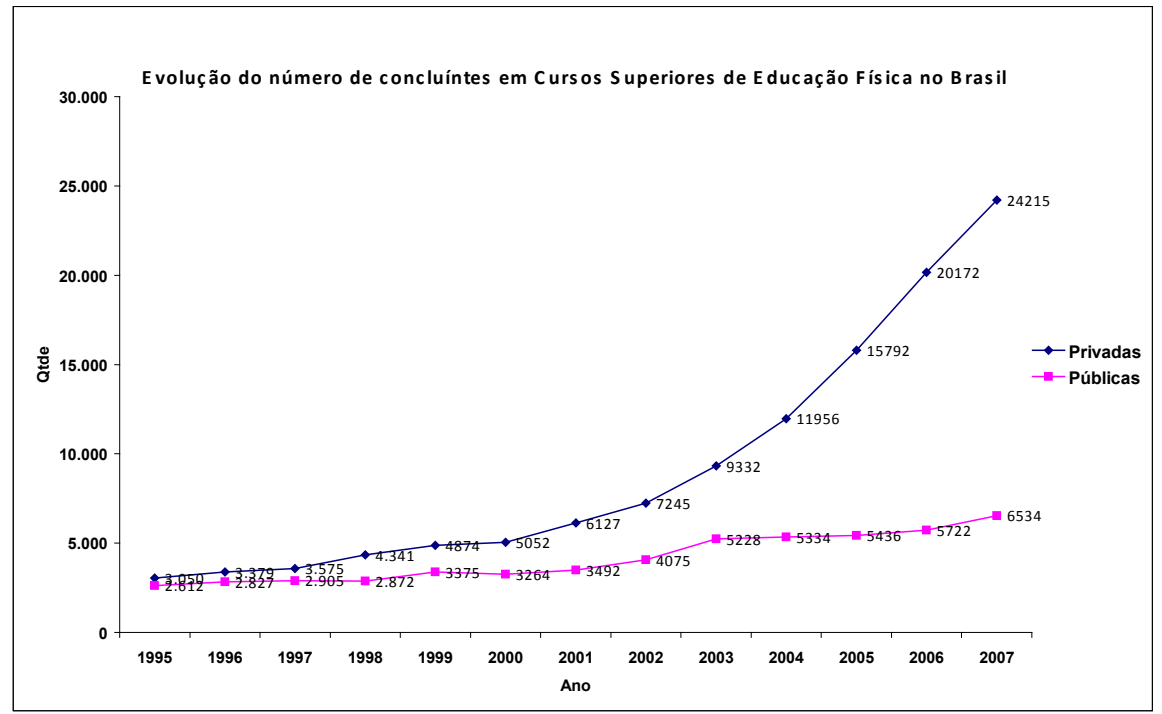

Figura 2. Gráfico de distribuição percentual evolutiva do número de concluintes em cursos privados e públicos em Educação Física. 
Esse panorama de crescimento e investimento privado no ensino superior pode ser melhor explorado quando analisamos o número de concluintes em instituições privadas no ano de 2007 que, comparado com instituições públicas, é aproximadamente $370 \%$ maior. O ensino superior encontra-se em ampla expansão e, para o caso da Educação Física, os dados sinalizam ainda maior interesse das instituições privadas nesta formação e para além dela, vislumbrando a expansão de um mercado de bens e serviços vinculados às práticas corporais.

Para melhor compreensão desses dados, há necessidade de os localizarmos no contexto político-econômico internacional que pode lhes dar sentido, pois "o contexto da globalização, do neoliberalismo e da reestruturação produtiva institui novas regras para a vida societária e impõe também novas formas de olhar e refletir a realidade social em níveis locais e global num projeto de formação acadêmico-profissional" (DAVID, 2009 , p. 01). É com esta preocupação que destacamos alguns dados a seguir.

\section{Alguns dados do contexto internacional para o ensino superior}

Dentre os mais fortes indicadores no contexto internacional, encontram-se os dados do Banco Mundial (2002) que apresenta importantes documentos de análise do contexto brasileiro. Segundo este Banco (2002, p. 20), em 1999, o sistema privado de ensino superior brasileiro contava com 1,5 milhões de estudantes, sendo responsável por $65 \%$ da formação neste nível, enquanto o sistema público, somados os níveis federal, estadual e municipal, era responsável por 35\%, com 830 mil estudantes. Com estes dados, o diagnóstico indicava que o país já era o oitavo em percentual de exploração deste nível de ensino pela iniciativa privada[4]

Nesse mesmo relatório, o Banco Mundial (WORD BANK, 2002, p. 22) informava que o percentual de incremento do ensino superior no Brasil no período compreendido entre 1980 a 1997 havia sido de 36\%, bastante inferior à média da América Latina. Naquele período, o Chile aparecia com um incremento de 167\%, seguido do Uruguai e Argentina com percentuais na casa dos 60-70\%. Este dado era, também, inferior ao crescimento de todos os países da Organisation for Economic Co-Operation and Development (OECD), cujos índices variavam de 353\% na Coreia a $47 \%$ nos Estados Unidos.

O destaque a esse documento, porém, decorre da avaliação feita pelo Banco Mundial acerca do ensino superior naquele período, avaliando o quadro brasileiro como de "estagnação do crescimento", indicando que a situação só era mais "dramática" em dois outros países do continente: Guatemala e México (WORLD BANK, 2002, p. 22). Havia, então, potencial de crescimento a ser explorado como indicava aquela avaliação.

É, também, nessa ótica que pode ser compreendida as Declarações de Doha (Organización Mundial del Comercio, 2001)[5], a qual, objetivamente, trata da liberalização da educação, transformando-a de sua condição de bem público em serviço a ser comercializado na esfera do mercado internacional. Esta declaração, subscrita pelos países membros da Organização Mundial do Comércio (OMC), permitia a livre circulação do capital, tal como já apontava Gazzola (2002).

Ao arrolar a educação como um item de serviço a ser regulamentado pelo Acordo Geral sobre Pautas Aduaneiras e Comércio, cuja sigla em inglês é que se tornou conhecida 
(General Agreement on Tariffs and Trade, GATT) [6], estariam dadas as condições para a remoção dos obstáculos à sua completa mercantilização. Passariam a vigorar para os então chamados serviços educacionais as mesmas normas atinentes aos demais serviços. Equivalência de diplomas, padrões para a formação profissional, validação de títulos estrangeiros e certificação de competências são, entre outros, exemplos do que passaria a obedecer à legislação da $\mathrm{OMC}$, sendo, por isto, mantidos fora do alcance de qualquer legislação nacional. De imediato, é transferida para os interesses comerciais mais vorazes a gestão da educação, afastando o Estado de uma de suas responsabilidades estruturais.

Com esse potencial de mercado constituído, ainda que não sem resistência dentre os países membros da OMC, a educação passa a integrar um dos doze setores a serem submetidos às regras do GATT[7]. Sob a vigência de tais regras, a educação passa a operar em "bases comerciais" e o seu "significado se refere, sem dúvida, a comércio, e remete à ideia de lucro" (RIBEIRO, 2006, p. 146).

É nesse cenário que menos de uma década depois daquele estudo do Banco Mundial (2002) [8] mencionado anteriormente, observamos significativa alteração do quadro do ensino superior na América Latina. O Brasil vem tendo um incremento do número de vagas muito superior a todos os demais países do continente, evidentemente, em decorrência das instituições privadas muito mais que das instituiçoes públicas. A seguir, apresentamos o gráfico com os dados referentes ao número de matriculados no ensino superior nos países latino-americanos mencionados anteriormente, de forma a melhor demonstrar o contexto nesta nova década, sobretudo em comparação com o Chile que apresentava taxas de crescimento bastante altas no período anterior, além da Guatemala e México, considerados em "situação dramática" naquele mesmo período.

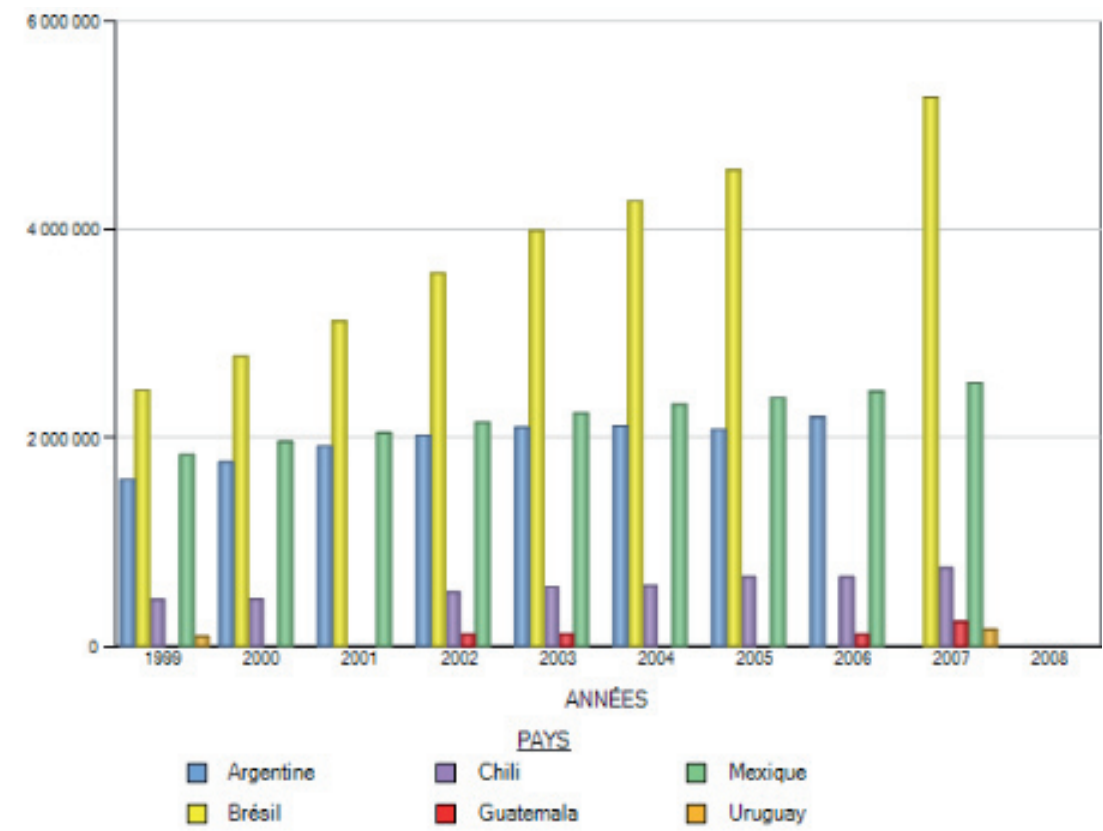

Figura 3 - Total de estudantes matriculados em Cursos Superiores ${ }^{1}$.

1 Gráfico produzido pela fonte: http://stats.uis.unesco.org/unesco/TableViewer/tableView.aspx, sob o título original na língua francesa: DONNÉES:Effectifs scolaires dans tous les programmes Supérieur. 
O quadro seguinte,com o número totalde matriculados no ensino superior, expressa um comparativo com outros países considerados em desenvolvimento e que compõem o denominado "BRIC"; juntamente com o Brasil, estão Rússia, Índia e China. O gráfico também apresenta, à guisa de comparação, dados relativos a dois países considerados desenvolvidos, Estados Unidos e Coreia, mencionados anteriormente por suas taxas de crescimento.

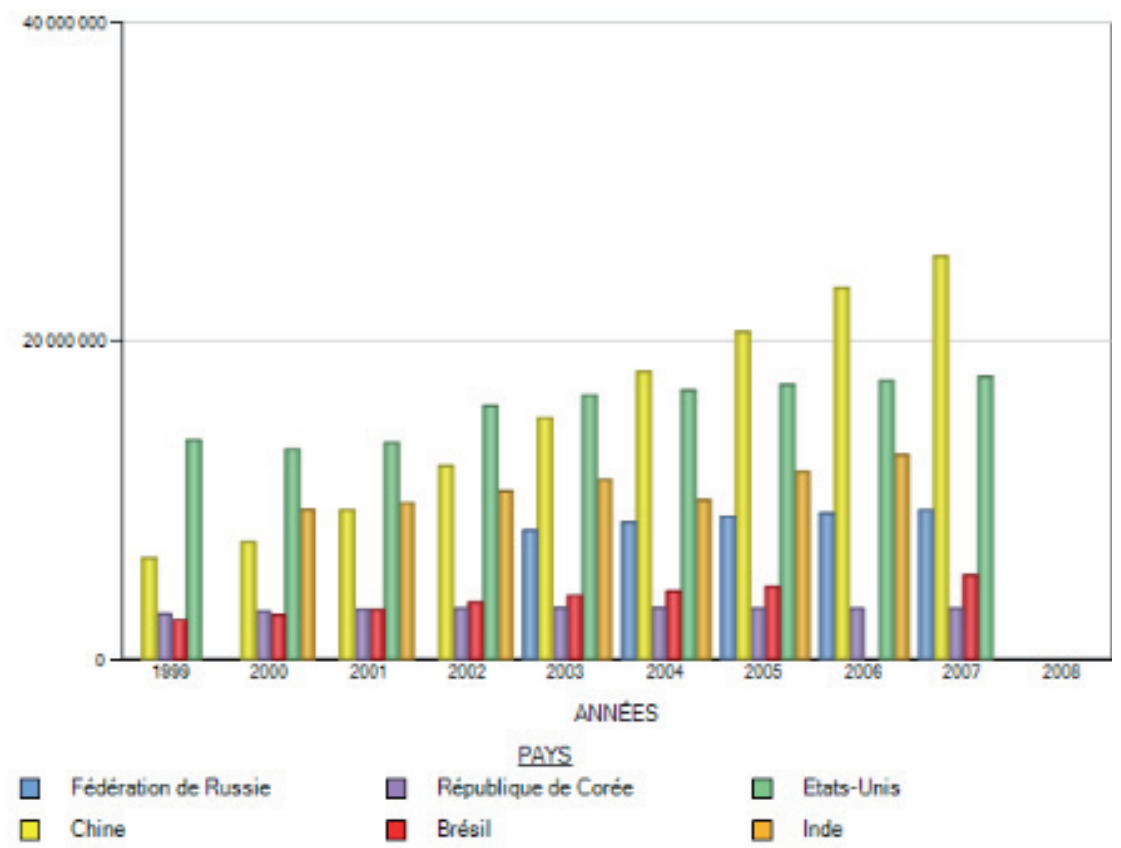

Figura 4. Total de estudantes matriculados em Cursos Superiores ${ }^{2}$

Tal panorama educacional apresenta alguns dados das realidades nacional e internacional, sinalizando indicadores importantes no mapeamento dos investimentos na Educação Física, além de permitir-nos pensar politicamente sobre a expansão acelerada do ensino superior no Brasil, notadamente neste campo. A responsabilidade estrutural do Estado brasileiro parece estar recuando diante de leis do mercado internacional, ainda que se possa acompanhar um certo movimento diferenciado no momento, com a criaçao de novos programas de expansão do ensino público. Apesar disso, o Estado não parece criar resistência à exploração da educação por parte da iniciativa privada, ao ampliar, sobretudo no âmbito das diretrizes e marcos legais, assim como das políticas de avaliação, a abertura de novos cursos e as possibilidades para entrada de novas empresas neste mercado de serviços.

A responsabilidade do Estado com a qualidade do ensino, assim como o impacto sobre o perfil e a intervençao profissional, deveria enfrentar estes elementos e buscar superar planejamentos e estratégias frágeis e pontuais, ajustados por determinantes mercadológicos. Desde o início do processo de formação

2 Gráfico produzido pela fonte: http://stats.uis.unesco.org/unesco/TableViewer/tableView.aspx, sob o título original na língua francesa: DONNÉES: Effectifs scolaires dans tous les programmes. Supérieur. 
profissional em Educação Física, observamos uma ação dúbia por parte do Estado, gerando ou reforçando dualidades e reducionismos presentes na concepção deste campo, como indicaremos a seguir.

\section{Formação profissional em Educação Física: marcas do processo político-econômico}

No sentido de melhor compreender a tessitura social da formação em Educação Física e explorar a hipótese de trabalho apresentada anteriormente, destacamos algumas características e finalidades identificadas durante sua trajetória no campo educacional brasileiro. Exploramos alguns elementos históricos que ajudam materializar os dados apresentados, discutindo brevemente algumas concepções identificadas no processo histórico de consolidação deste campo.

Ao analisarmos a formação profissional, é importante lembrar da fundação em 1922, no Rio de Janeiro, do Centro Militar de Educação Física que forma a primeira turma de profissionais neste campo em 1929, ainda que em caráter provisório. Compunham esta turma oito oficiais instrututores, sessenta monitores, dois médicos militares e vinte professores civis (MARINHO, 1980). Este Centro dará origem, mais tarde, a Escola de Educação Física do Exército, com o reforço de várias instâncias sociais, dentre essas, as teses aprovadas durante o I Congresso Brasileiro de Eugenia (MELO, 1996, p. 37).

A relação da Educação Física com os militares e os médicos tem sido bem explorada academicamente nas pesquisas de campo e, em geral, pensa-se numa certa subserviência desta em relação as outras duas instituições. Para as questões ligadas à formação profissional, podemos pensar na possibilidade de que a Educação Física teria usufruido do referencial teórico e força política do movimento higienista, para superar seus problemas de identidade e legitimidade, mantendo uma forte relação com a Medicina e a Biologia, como indicam Góis Júnior e Loviloso (2003), talvez, como uma forma dos educadores se contraporem ao predomínio militar neste âmbito de intervenção social. Assim, para a Educação Física em seu processo de institucionalização, a relação com este campo biomédico teria sido interessante, assim como também com os educadores e filósofos, ainda que estas relações ocorressem mais no plano teórico e político e menos no cotidiano do trabalho que permanecia referenciado no ideário militar, como nos indica Melo (1996). Vemos, então, constituir-se, neste processo, as ambiguidades entre educação e saúde, alicerçadas numa forte dualidade entre um referência teórica fundamentada na saúde e uma prática constituída no exercício da caserna.

Melo (1996) informa ainda que o primeiro curso voltado a civis em Educação Física inicia suas atividades em 1931 no Espírito Santo. De forma mais sistemática, porém, é no Estado de São Paulo, no ano de 1934, que se verá o início da formação profissional sistemática e, em 1939, o primeiro curso de graduaçao em nível superior na Escola Nacional de Educaçao Física e Desportos (ENEFD) na Universidade do Brasil, com dois anos de duração. No ano anterior, junto a Escola Superior do Exército, o Departamento de Educação Física do Ministério da Educação (DEF MEC) realiza cursos em caráter emergencial com uma proposta que nos permitirá 
identificar a ocorrência de uma primeira dualidade na formação em Educação Física, com dois profissionais distintos: o instrutor de Educação Física para atuar junto a sociedade civil, e o professor de Educação Física, para atuar na docência e também na ENEFD (AZEVEDO; MALINA, 2004).

Nessas primeiras décadas do século XX, o país atravessava uma importante fase de mudanças sociais, econômicas e políticas em que novas formas de preconceito de classes sociais em ascensão tomam forma. Essa ideologia vigente apoia-se em valores culturais europeus, assim como numa perspectiva positivista de ciência, educação e política, para modelar seus padrões e condutas, modos e costumes. Neste contexto, a dimensão corporal cumpre papel secundário no cenário nacional, carregando consigo heranças coloniais que viam em qualquer tipo de trabalho manual a desvalorização da mão-de-obra servil ou escrava. Em vista disso, Oliveira (1998, p. 5) descreve que "[...] a estrutura colonial rendia dividendos ideológicos e aumentava o preconceito em relação ao trabalho físico", mostrando-nos um aspecto social contraditório, com o impulso político que a Educaçao Física obteria.

Como já indicamos acima, naquele período e, em grande medida, até o momento, a fundamentação teórica mais valorizada na Educação Física era proveniente das ciências biomédicas, com sua concepção anatomo-fisiológica e higienista de ser humano e sociedade. Embora a Educação Física tenha se tornado uma aliada no âmbito da saúde pública em função da posição médica que viam nesta um reforço no combate às doenças, tornou-se, também, uma referência fundamental no projeto social de controle do povo e de civilidade. Assim, a sua base de sustentação e consolidação modelou-se nesse conjunto de interesses, sobretudo na relação com as forças sociais dominantes desse período histórico, quer sejam os militares, quer sejam os médicos ou os educadores, tornando-se um instrumento de ordem recebendo "o reforço científico” (SOARES, 2001, p. 95). A formação profissional em Educação Física na primeira metade do século passado já apresentava suas ambiguidades, pois nos currículos das escolas de formação, o fundamento teórico era fornecido pelos médicos e biológos, enquanto a prática pedagógica, a didática e a disciplina ficavam sob o comando dos militares.

Não se pode, assim, deixar de destacar a ginástica no cenário da Educação Física brasileira, sobretudo por conta do seu papel desempenhado nas primeiras décadas da formação profissional específica, conforme demonstraram pesquisas de Soares (2001; 2006; 2009), por ser identificada como um eixo central na formação específica. As ginásticas naquele período, seja no meio militar ou a partir dos militares na formação de civis, destacavam-se sobre as demais práticas corporais e tiveram papel marcante na relação teoria e prática na primeira metade do século XX, no sentido de estabelecer a necessidade de se fazer exercícios, bem como de um profissional que a instrua. Importante ressaltar que o perfil dos instrutores e também dos professores que se seguiram era firmemente calcado no domínio do conhecimento prático, com um descaso ao fundamento teórico-metodológico deste saber fazer. Às ginasticas logo se agregou o esporte e, para tal, logo convocou-se os principais esportistas para atuar nos cursos de formação profissional, como mostram Azevedo e Malina (2004, p. 32).

Tal processo propiciou a criação das primeiras escolas de Educação Física dentro de um modelo curricular denominado de "tradicional-esportivo" (BETTI; BETTI, 
1996). Essa visão era vinculada à prática da ginástica e à valorização das modalidades esportivas, baseada na exercitaçao sistemática e nos modelos para transmissão de conhecimentos. De acordo com Barros (2001, p. 9), é um fato que a Educação Física no Brasil, inicialmente, desenvolveu-se nas escolas militares, mas "[...] também sempre esteve conectada ao sistema educacional e toda legislação específica veio junto com a legislação educacional em geral”. Em outras palavras, os militares efetivamente desempenharam um forte papel no processo de consolidação e desenvolvimento da Educação Física, contudo, foi no âmbito escolar, sob o discurso biomédico, que ela conquistou espaço no cenário social.

Entendendo a construção da identidade da Educação Física como um campo de disputa e tensão, observamos um discurso organizado sob a égide das ciências biomédicas, e uma prática pedagógica, tanto no âmbito da formação profissional como da intervenção social, calcada quase exclusivamente na demonstração de modelos e no saber fazer. Ainda que construída como licenciatura, portanto, voltada à formação de professores desde sua constituição no nível superior, foi separada das demais licenciaturas em termos administrativos (MELO, 1996) e não havia pedagogia ou disciplinas pedagógicas no currículo da formação profissional, ao menos, até a década de sessenta, como informam Azevedo e Malina (2004).

As raízes culturais da Educação Física mostram a valorização do conhecimento prático, direcionado para a experiência prática e execução de técnicas corretas e eficazes de movimento. $\mathrm{O}$ ensino centrava-se no saber fazer. Esta era a ênfase, ainda, quando da reforma do ensino superior deflagrada após o golpe militar de 1964 e a partir dos acordos assinados com a Agência de Desenvolvimento Internacional dos Estados Unidos (USAID). Azevedo e Malina (2004) informam que, para a reforma curricular específica, o Departamento de Educação Física do Ministério da Educação designa, em 1968, um grupo de trabalho coordenado pela professora Maria Lenk, diretora do ENEFD, com diretores de outras escolas de Educação Física do país. Este grupo produz a resoluçao n. 09/69 que introduz as disciplinas de cunho pedagógico no currículo da licenciatura em Educaçao Física, porém não garantindo a unidade curricular ou a incorporação destas nas escolas de formação. Em entrevista com alguns dos professores que participaram daquele grupo, inclusive a diretora do ENEFD, os autores acima citados informam que seus depoimentos indicam que a decisão política, sobretudo desta Escola e copiada pelas demais país afora, foi de remeter os professores responsáveis por estas disciplinas, tais como história e administração, para as Faculdades de Educação (AZEVEDO; MALINA, 2004, p. 135). O mesmo procedimento foi utilizado, também, com as disciplinas da área médica.

Identificamos, então, que se perdeu uma oportunidade histórica de construir uma unidade entre teoria e prática, em fundamentar academicamente a formação profissional e a intervenção social decorrente de seus egressos. A decisão política que prevaleceu foi afastar esses professores e o diálogo profícuo que poderiam ser travado entre eles e aqueles responsáveis pelas práticas corporais, tais como a ginástica, os esportes e os jogos recreativos se perdeu. Apesar da reforma curricular, a formação permaneceria, assim, eminentemente técnica, ao menos, por mais duas décadas. Ainda sob os auspícios do Estado Novo, a legislação em vigor - o DecretoLei n. 5343 de 1943 - manteve a equiparação, para todos os efeitos, dos instrutores 
de Educação Física formados pelas Escolas do Exército, aos licenciados em Educação Física (BAPTISTA, 2002).

Paralelamente à abertura política e à possibilidade concreta de alteração das políticas implantadas no período da ditadura militar, cresce no país a importância da ciência e tecnologia e o paralelo desejo de status social, centrando as exigências na obtenção de conhecimentos teóricos. A construção de novas perspectivas políticas para a educação e para a intervenção social, gestadas no interior do movimento pela abertura política, é acrescida da importância atribuída ao saber científico, torna-se uma nova base para o reconhecimento social, econômico e político, uma vez que se tornou o "[...] elemento essencial para a aquisição de autoridade e inserção na hierarquia posicional vigente dentro do campo profissional" (VENUTO, 1999, p. 1).

É nesse contexto de abertura política e da crescente força produtiva da tecnociência que o modelo curricular migra do "técnico-esportivo", citado anteriormente, para o modelo de "orientação técnico-científico" (BETTI; BETTI, 1996, p. 10). O modelo teórico fundamentado nos moldes científicos levou o profissional de Educação Física a buscar subsídios especializados e a valorizar tais conhecimentos. Os cursos tiveram um aumento significativo de disciplinas teóricas com uma valorização destas em relação às chamadas disciplinas práticas ou técnicas, mais ligadas às práticas corporais. Esta visão mais academicista contribuiu para um distanciamento entre o saber científico e o saber fazer e, mais, nesse momento não focalizou suas preocupações para a práxis pedagógica. Além do reforço à dicotomia teoria e prática, ampliou-se a dualidade formação e intervenção.

Paralelamente a essa discussão, também, observamos um questionamento à chamada "falta de flexibilidade" do currículo, sintoma de uma demanda de mercado que se amplia e se complexifica, assim como do mercado do ensino superior que vai se expandindo. É nesta perspectiva que se pode compreender a reestruturação curricular dos cursos de Educação Física, com a Resolução n. 03/87 do, então, denominado Conselho Federal de Educação. Com este novo marco legal, estava permitida a quebra da formação, de profissional generalista caracterizado pelo ato de educar como vinha se organizando, para a licenciatura e o bacharelado. A dualidade na formação fica instituída, com "a reestruturação dos cursos de graduação em educação física, onde impunham novos conteúdos e perfis profissionais diferenciados que os currículos necessitavam atender" (BARROS, 2001, p. 14).

A quebra na formação e a dualidade de diretrizes, juntamente com um mercado interessado em campos de conhecimento e intervenção cada vez mais numerosos e especializados, levantam mais inquietações no cenário brasileiro. Outra dessas inquietaçoes é a crescente multiplicidade de formações no campo da Educação Física para além da licenciatura e bacharelado já mencionados. De acordo com o Cadastro de Instituições de Ensino Superior, são encontrados diferentes cursos a partir da mesma raiz comum, tais como gestão do esporte; gestão em lazer, bacharelado em esportes; atividade física e esporte; ciência do esporte; promoção de eventos, esporte e lazer; treinamento físico e esportes, dentre outros.

Sinalizamos o distanciamento entre as diferentes formações que decorrem da raiz comum Educaçao Física, como consequência de uma política econômica neoliberal que aceita, ainda que por omissão, a transformação da educação de sua condição 
de bem público para a condição de serviço, onde passa a ser mercadorizada[10]. Tal fragmentação do campo permite melhor exploração comercial e está alicerçada em políticas educacionais que remodelam políticas públicas que eram consideradas restritivas e retrógradas por limitar a ação do capital privado no âmbito do ensino superior e, consequentemente, na Educação Física. Esta "nova” política educacional que fragmenta este campo específico, não apenas desprestigia e desvaloriza a luta dos setores progressistas da área por uma identidade alicerçada numa formação generalista e competente fundada na compreensão do direito de acesso a cultura corporal, como reforça um processo de alienação na formação para o trabalho, reforçando as dicotomias entre teoria e prática, público e privado, formação ampliada e formação especializada, ratificando o discurso em voga e reforçando uma trajetória histórica conservadora que está em curso no país desde o início do século passado. A educação, como processo sistemático de formação humana, de produção e socialização do conhecimento sistematizado pela humanidade, passa a estar cada vez mais constituída a partir dos discursos da eficácia, do lucro e da competitividade provenientes do mundo da economia política.

\section{Considerações finais}

Em face dos indicadores dos contextos nacional e internacional e, também, daqueles presentes na história da Educaçao Física, nossa hipótese de trabalho confirmou-se com a forte presença de determinantes políticos e econômicos atuando no campo. Com estas indicações, buscamos construir subsídios para analisar a situação atual da formação profissional, assim como do tipo de intervenção que os profissionais sao levados a construir em seu cotidiano como trabalhadores. Ressaltamos a necessidade de estar atento às novas exigências decorrentes do mercado que, ao mercadorizar bens e serviços na educação faz por difundir necessidades e linguagens, estabelecendo um grande número de novos cursos, fragmentando o conhecimento que decorre da mesma raiz comum da Educação Física. Tais demandas e interesses geraram mudanças estruturais nas instituições de ensino superior e, especialmente, um tipo de formação profissional cada vez primando pela especialização, o que traz importantes implicações éticas, políticas e epistemológicas em um campo estratégico pela interconexão que estabelece com a educação e a saúde.

A separação da Educação Física em campos distintos, licenciatura e bacharelado, passando de uma formação generalista, ainda que com todos os problemas que pudesse apresentar, para formação especialista, contribuiu para o afastamento da teoria e prática e para um processo de fragmentação da formação e da intervenção profissional. O que podemos observar neste processo de fragmentação atendendo aos ditames do mercado é o reforço e consolidação de um discurso cientificista, com fortes marcas biomédicas que se pautam pelas formas de controle e disciplinamento dos corpos. Por uma via particular, a trajetória de formação profissional em Educação Física acabou por contribuir com a desvalorização do trabalho manual, por mais contraditória que esta idéia possa parecer, optando por servir aos interesses do mercado a partir dos códigos da cientificidade racionalista que vigoram na modernidade, reforçando, ainda, a dualidade na relação pesquisador e professor. 
Essa fragmentação,identificada na Educação Física, demonstra uma relação desigual inclusive nos campos de atuação profissional específicos, com uma desvalorizaçao daqueles professores que irão atuar no sistema oficial de ensino, por sua vinculação com a educação e a pedagogia. Do contrário, uma valorização daqueles que irão atuar em outros ambientes como profissionais liberais, notadamente no mercado de academias e de treinamento esportivo que se amparam num conjunto de conhecimentos produzidos, majoritariamente, de uma perspectiva reducionista de ciência e de forma descolada da intervenção profissional. Mais do que isso, desprezando o elemento central caracterizado no ato de ensinar, característico de todas as intervenções profissionais em Educação Física e que fundamenta uma perspectiva de formação generalista, abre mão, também, de uma perspectiva ética e política esperada como contribuição social, ao direcionar seu currículo para atender as demandas do mercado de trabalho e para reforçar este ciclo, na formação de pesquisadores (DAVID, 2002).

A construção de identidades, licenciatura e bacharelado, e a contínua fragmentação da formação que se pode acompanhar, ao serem implantadas para sanar demandas de mercado, além de não qualificarem política e academicamente à formação, fragilizam o campo da Educação Física. Engessam, assim, as possibilidades de discussão e reflexão e, mais, de efetiva contribuição social.

A reflexão acerca dessas questões político-econômicas alerta para tensionamentos e mecanismos de poder interiorizados no processo social educacional e de formação profissional em Educação Física, expressos em alguns discursos científicos tradicionais, na materialização de leis, diretrizes, conselhos e investimentos destinados para a área. $\mathrm{O}$ apoio, a abertura e o investimento do Estado para a rápida propagação e desenvolvimento de instituições de ensino superior privado é um dado preocupante, visto a transferência de responsabilidades e deveres deste com o ensino, a proliferação acelerada, sem medidas e controles qualitativos de implantação e acompanhamento, bem como as restrições presentes nestes setores, com finalidades de rendimento e lucro definidas em sua constituição, portanto, sempre preza as demandas e exigências do mercado.

Entendemos, portanto, que as indagações levantadas sobre os interesses do globalizado mercado nacional e internacional sobre a Educação, o crescimento das instituições privadas de ensino apoiadas por políticas neoliberais, trazem subjacente outras discussões presentes na racionalidade técnica científica, nas dualidades e contradições da formação profissional em Educação Física, como também na expectativa e status social atribuídos ao profissional da área. O novo panorama educacional, apresentado aqui por meio dos indicadores objetivos, sugere maiores possibilidades de acesso ao ensino superior. Em nosso entendimento, porém, mascaram uma precarização do ensino superior com um descompasso entre a produção do conhecimento e a intervenção social, operando sob a êgide de um discurso globalizado e produtivista.

\section{Professional Education in Physical Education and the Social Political Process}

\footnotetext{
Abstract

This article discusses some of the important issues which permeate professional education in Physical Education in Brazil. This resarch work was conducted through content analysis of official documents and
} 
databases from the Brazilian government as well as other documents from international organisations. Data investigation shows that more than 100 thousand BA placements in physical education are made available each year in Brazil, which ranks it among the 10 courses with the largest number of graduating students in the country. Also, this research shows that political and economic elements which are linked to emerging market demands and interests guide the needs of the social process of professional education in physical education.

Keywords: Physical Education - Professional Education - Educational Policies

\section{La Formación Profesional en Educación Física y el Proceso Político Social}

\section{Resumen}

Este artículo discute algunos determinantes que sustentan la formación profesional en Educación Física en Brasil. En la investigación, de tipo documental con técnica de análisis de contenido, se ha trabajado con documentos y bancos de datos oficiales del gobierno brasileño, además de otros procedentes de organismos internacionales. Los datos de la investigación indican que cada año se ofrecen más de 100 mil plazas en Educación Física, convirtiéndolo en uno de los 10 mayores cursos en número de graduados en el país. Cabe observar que, ciertos elementos político-económicos vinculados a los intereses y demandas emergentes de mercado, son los que dirigen las necesidades del proceso social en la formación profesional en Educación Física.

Palabras clave: Educación Física - Formación Profesional - Políticas Educacionales

\section{Referências}

AZEVEDO, A. C. B; MALINA, A. Memória do currículo de formação profissional em educação física no Brasil. Revista Brasileira de Ciencias do Esporte, Campinas, Autores Associados, v. 25, n. 02, p. 129-142, 2004.

WORD BANK.2002.Disponívelem: <cf.http://go.worldbank.org/AQCVCDGCU0>. Acesso em: 12 maio, 2009.

BARROS, J. M. de C. Formação profissional em educação física no Brasil: um novo momento. Rio Claro/SP: Departamento de Educação Física - I.B./UNESP, 2001.

BAPTISTA, M. T. A influência da escola de educação física do exército na origem do currículo de educação física no Brasil. Revista de Educação Física, n. 126, p. 10-14, 2002.

BETTI, M; BETTI, R. Novas perspectivas na formação profissional em educação física. Revista Motriz. Rio Claro/SP, v. 2, n. 1, p. 10-15, jun. 1996.

BRASIL. Lei n ${ }^{\circ}$ 10.861, de 14 de abril de 2004. Institui o Sistema Nacional de Avaliação da Educação Superior. Diário Oficial [da República Federativa do Brasil], Brasília, DF, 15 de março, 2004.

DAVID, N. A. N. A formação de professores para a Educação Básica: dilemas atuais para a Educação Física. Revista Brasileira de Ciências do Esporte. Campinas/SP, v. 23, n. 2, p. 119-133, jan. 2002.

. A formação profissional docente em educação física: dicotomias e rupturas no campo da formação e da prática. In: CONGRESSO GOIANO DE CIÊNCIAS DO ESPORTE, 6, 2009. Goiânia, Anais... Disponível em: <http://www.rbceonli- 
ne.org.br/congressos/index.php/congoce/VICONGOCE/paper/view/1847/395> Acesso em: 29 jun. 2009.

GAZZOLA, A. L. A. Educação superior: bem público ou mercadoria? Jornal da Ciência, n. 2.030, 10 maio 2002. Disponível em: <http://www.jornaldaciencia.org.br/ Detalhe.jsp?id=2178>. Acesso em: 19 maio 2009.

GÓIS JÚNIOR, E.; LOVISOLO, H. R. Descontinuidades e continuidades do movimento higienista no brasil do século XX. Revista Brasileira de Ciências do Esporte, Campinas, v. 25, n. 1, p. 41-54, set. 2003.

INEP. Sistema nacional de avaliação da educaçãosuperior: da concepção à regulamentação. Brasília/DF, 2007. Disponível em: <http: //www.sinaes.inep.gov.br/sinaes/>. Acesso em: 06 abr. 2009.

MARINHO, I. P. História geral da educação física. São Paulo: Cia Brasil Editora, 1980 .

MELO, V. A. Escola nacional de educação física e esportes: uma possível história. Dissertação (Mestrado em Educação Física), Universidade Estadual de Campinas, Campinas, 1996.

OLIVEIRA, V. M. Formação profissional: primeiras influências. Revista Brasileira de Ciências do Esporte, v. 19, n 2, p. 4-13, jan. 1998.

ORGANIZACIÓN MUNDIAL DEL COMERCIO. Declaraciones de Doha. 2001. Disponível em: <http://www.wto.org/spanish/res_s/booksp_s/ddec_s.pdf>. Acesso em: 18 maio 2009.

PAIVA, F. S. L.; ANDRADE FILHO, N. F.; FIGUEIREDO, Z. C. C. Formação inicial e currículo no CEFD/UFES. Revista Pensar a Prática. Goiânia/GO, v. 9, n. 2, p. 213-230, jul./dez. 2006.

RIBEIRO, G. F. Afinal, o que a Organização Mundial do Comércio tem a ver com a educação superior? Revista Brasileira de Politica Internacional. v. 49, n. 2, p. 137-156, 2006.

SANTOS, A. L. P.; SIMÕES, A. C. Desafios do ensino superior em educação física: considerações sobre a política de avaliação de cursos. Revista Ensaio. Rio de Janeiro, v. 16, n. 59, p. 259-274, abr./jun., 2008. Disponível em: <http//www.scielo.br/pdf/ ensaio/v16n59a06.pdf>. Acesso em: 02 fev. 2009.

SOARES, C. L. Educação física: raízes européias e Brasil. 2. ed. Campinas: Autores Associados, 2001.

. Imagens da educação no corpo. 3. ed. Campinas: Autores Associados, 2006.

. Da arte e da ciência de movimentar-se: primeiros momentos da Ginástica no Brasil. In: DEL PRIORE, M.; MELO, V. A. de (Org.). História do esporte no Brasil: do Império aos dias atuais. 1 ed. São Paulo: Editora da Unesp, 2009. p.73-89. 
TAFFAREL, C. Z.; LACKS, S.; SANTOS JÚNIOR, C. L.Formação de professores de educação física: estratégias e táticas. Motrivivência. Ano XVIII, n. 26, p. 89-112, jun. 2006.

VENUTO, A. A Astrologia como campo profissional em formação. Revista de Ciências Sociais. Rio de Janeiro, v. 42, n. 4, p. 1-27, 1999.

[1] Para maioresinformações,conferirhttp://www.inep.gov.br/superior/censosuperior/ sinopse/, para número de novos professores e o site http://www.inep.gov.br/ superior/censosuperior/evolucao/evolucao.htm, referente a posição do curso em relação aos demais.

[2] Nas primeiras colocações encontram-se os cursos de Administração, Direito, Pedagogia, Engenharia, Comunicação Social, Enfermagem e Ciências Contábeis, respectivamente.

[3] Dadosextraídosdosite:http://www.inep.gov.br/download/superior/censo/2007/ Resumo_tecnico_2007.pdf. Acesso em: 10 maio, 2009.

[4] Por ordem decrescente, o maior percentual era apresentado pelas Filipinas, seguida do Japão, Republica Dominicana, El Salvador, Colômbia, Bélgica e Indonésia.

[5] As Declarações de Doha decorrem do encontro da Organização Mundial do Comércio realizado na cidade que dá o nome ao documento, no período de 9 a 13 de novembro de 2001.2009.

[6] Os doze setores referidos são 1. negócios (como os serviços profissionais jurídicos, de contabilidade e de arquitetura); 2. comunicação (como os serviços postais e de telefonia); 3. construção e serviços de engenharia; 4. distribuição; 5. educação (como a educação superior); 6. meio ambiente (como serviços de saneamento); 7. financeiro; 8. saúde; 9. turismo e viagem; 10. recreação, cultura e esporte; 11. transporte; 12 . serviços de cunho genérico.

[7] Os doze setores referidos são 1. negócios (como os serviços profissionais jurídicos, de contabilidade e de arquitetura); 2. comunicação (como os serviços postais e de telefonia); 3. construção e serviços de engenharia; 4. distribuição; 5. educação (como a educação superior); 6. meio ambiente (como serviços de saneamento); 7. financeiro; 8. saúde; 9. turismo e viagem; 10. recreação, cultura e esporte; 11. transporte; 12 . serviços de cunho genérico.

[8] Em maio de 2009, o Banco Mundial mantinha apenas sete projetos de financiamento ativos no Brasil, envolvendo a Educação, nenhum deles no âmbito do ensino superior. $O$ banco de dados daquela instituição mostra que todos os contratos feitos com o Brasil para o Ensino Superior encontram-se encerrados ou abandonados (cf. http://go.worldbank.org/ AQCVCDGCU0). 
[9] Os próximos gráficos são construídos a partir do banco de dados do UNESCO Institut for Statistics (UIS), disponível em <http://stats.uis.unesco.org/unesco/ TableV iewer/tableView.aspx>. Acesso em: 20 maio, 2009.

[10] Esta transformação foi operada em âmbito internacional desde a reunião da Organização Mundial do Comércio, realizada em Doha (2001), conforme mencionado anteriormente, e reiterada em outros documentos internacionais do Fundo Monetário Internacional (2003).

Recebido em: 02 de junho de 2009

Revisado em: 07 de julho de 2009

Aprovado em: 07 de julho de 2009

\section{Endereço para correspondência}

anamarcia@pq.cnpq.br

Ana Márcia Silva

Labphysis - Laboratório de Pesquisa em Educação Física, Sociedade e Natureza

Faculdade de Educação Física

Universidade Federal de Goiás

Campus Samambaia, 131,

Cep 74.001-970

Goiania - Goiás - Brasil 